\title{
Expanded Terminal Fields of Gustatory Nerves Accompany Embryonic BDNF Overexpression in Mouse Oral Epithelia
}

\author{
Chengsan Sun, ${ }^{1}$ Arjun Dayal, ${ }^{2}$ and David L. Hill ${ }^{1}$ \\ ${ }^{1}$ Department of Psychology, University of Virginia, Charlottesville, Virginia 22904, and 2Pritzker School of Medicine, University of Chicago, Chicago, Illinois \\ 60637
}

\begin{abstract}
Brain-derived neurotrophic factor (BDNF) is expressed in gustatory epithelia and is required for gustatory neurons to locate and innervate their correct target during development. When BDNF is overexpressed throughout the lingual epithelium, beginning embryonically, chorda tympani fibers are misdirected and innervate inappropriate targets, leading to a loss of taste buds. The remaining taste buds are hyperinnervated, demonstrating a disruption of nerve/target matching in the tongue. We tested the hypothesis here that overexpression of BDNF peripherally leads to a disrupted terminal field organization of nerves that carry taste information to the brainstem. The chorda tympani, greater superficial petrosal, and glossopharyngeal nerves were labeled in adult wild-type (WT) mice and in adult mice in which BDNF was overexpressed $(\mathrm{OE})$ to examine the volume and density of their central projections in the nucleus of the solitary tract. We found that the terminal fields of the chorda tympani and greater superficial petrosal nerves and overlapping fields that included these nerves in $\mathrm{OE}$ mice were at least $80 \%$ greater than the respective field volumes in WT mice. The shapes of terminal fields were similar between the two groups; however, the density and spread of labels were greater in OE mice. Unexpectedly, there were also group-related differences in chorda tympani nerve function, with $\mathrm{OE}$ mice showing a greater relative taste response to a concentration series of sucrose. Overall, our results show that disruption in peripheral innervation patterns of sensory neurons have significant effects on peripheral nerve function and central organization of their terminal fields.
\end{abstract}

Key words: BDNF; chorda tympani; glossopharyngeal; greater superficial petrosal; terminal field

\section{Introduction}

The developing and adult rodent peripheral gustatory system is highly plastic. The unusual amount of plasticity may be due in part to the normal turnover of taste bud cells (Beidler and Smallman, 1965; Farbman, 1980), leading to corresponding changes in the receptive fields of gustatory neurons (Krimm and Hill, 1998, 2000).

The structure and function of the peripheral taste system is also susceptible to a wide array of experimental manipulations, including early prenatal dietary manipulations (Hill et al., 1986; Hill, 1987) and nerve section (Cheal and Oakley, 1977; Cheal et al., 1977; Whitehead et al., 1987; Sollars and Bernstein, 2000; Sollars et al., 2002; Shuler et al., 2004; Guagliardo and Hill, 2007). For each of these developmentally and experimentally induced changes in the peripheral limb of nerves that innervate taste buds, there are changes in the anatomical and functional organization of their central processes (Zhang and Ashwell, 2001; Mangold and Hill, 2008; Corson et al., 2013). However, it is not clear

\footnotetext{
Received June 6, 2014; revised 0ct. 28, 2014; accepted Nov. 14, 2014.

Author contributions: C.S. and D.L.H. designed research; C.S. and D.L.H. performed research; A.D. contributed unpublished reagents/analytic tools; A.D. and D.L.H. analyzed data; C.S. and D.L.H. wrote the paper.

This work was supported by the National Institutes of Health (Grants R01 DC00407 and and R01 DC007176). We thank Robin Krimm for providing editorial comments on an earlier version of the manuscript.

The authors declare no competing financial interests.

Correspondence should be addressed to Dr. David L. Hill, Department of Psychology, P.0. Box 400400, University of Virginia, Charlottesville, VA 22904. E-mail: dh2t@virginia.edu.

DOI:10.1523/JNEUROSCI.2381-14.2015

Copyright $\odot 2015$ the authors $\quad 0270-6474 / 15 / 350409-13 \$ 15.00 / 0$
}

whether the central effects are driven primarily by the peripheral alterations.

To address this problem, we used mice in which the neurotrophic factor brain-derived neurotrophic factor (BDNF) was overexpressed embryonically in the tongue, but not in ganglia or centrally. During normal development, BDNF plays a critical role embryonically in directing taste neurons to their target, taste buds (Krimm et al., 2001; Lopez and Krimm, 2006; Krimm, 2007; Ma et al., 2009). Moreover, BDNF is expressed in both emerging taste buds and in ganglion cells embryonically (Nosrat and Olson, 1995; Nosrat et al., 1996; Huang and Krimm, 2010) and at adulthood (Nosrat et al., 1997; Yee et al., 2003), indicating its potential life-long involvement in peripheral gustatory system organization. Genetically deleting BDNF or its receptor (TrkB) globally during early development dramatically decreases the normal numbers of taste buds and the number of neurons surviving to adulthood (Fritzsch et al., 1997; Nosrat et al., 1997; Zhang et al., 1997; Oakley et al., 1998; Oakley, 1998; Patel and Krimm, 2010; Patel et al., 2010).

In contrast, overexpression of BDNF in nongustatory areas of the tongue during embryonic development produces mice where chorda tympani nerve (CT) axons preferentially and inappropriately innervate filiform papillae (Krimm et al., 2001; Lopez and Krimm, 2006; Krimm, 2007; Ma et al., 2009). This ultimately yields fewer taste buds with more than normal numbers of geniculate ganglion cells (Krimm et al., 2001) and a hyperinnervation of remaining taste buds (Zaidi et al., 2007). Because the genetically 
driven molecular manipulation should not occur in the ganglia of gustatory neurons or their central targets, it is an ideal model system with which to examine how peripheral factors affect the terminal fields of gustatory neurons. The work presented here shows that, indeed, there are dramatic changes in the central organization of these terminal fields. Candidate mechanisms for these changes are proposed and tested.

\section{Materials and Methods}

\section{Animals}

All experiments were approved by the University of Virginia Animal Care and Use Committee and followed guidelines set forth by the National Institutes of Health and the Society for Neurosciences. Experimental animals were transgenic mice in which the expression of BDNF (overexpressors; OE) was enhanced under the control of a cytokeratin14 promoter. These mice have been fully described previously (LeMaster et al., 1999; Krimm et al., 2001). Control mice (wild-type; WT) were littermates lacking the transgene.

\section{Fluorescent anterograde nerve labeling}

Procedures used to label three nerves with fluorescent tracers were similar to that described in rat (May and Hill, 2006; Mangold and Hill, 2007). Briefly, the CT, greater superficial (GSP), and the glossopharyngeal (IX) nerves were labeled in OE ( $n=6: 3$ males, 3 females) and WT ( $n=6: 3$ males, 3 females) mice with anterograde tracers to determine the volume and densities of label among gustatory afferent terminal fields in the nucleus of the solitary tract (NTS; Fig. 1). All animals were between 3 and 5 months old. Mice were sedated with a $0.32 \mathrm{mg} / \mathrm{kg}$ intramuscular injection of Domitor (medetomidine hydrochloride: Pfizer Animal Health) and anesthetized with $40 \mathrm{mg} / \mathrm{kg}$ intramuscular Ketaset (ketamine hydrochloride: Fort Dodge Animal Health). A water-circulating heating pad was used to maintain body temperature. Mice were positioned in a nontraumatic head holder (Erickson, 1966) and a ventral approach was taken to expose the GSP and CT nerves within the right tympanic bulla. The CT and GSP nerves were cut near and peripheral to the geniculate ganglion in the tympanic bulla and crystals of $3 \mathrm{kDa}$ biotinylated dextran amine were then applied to the proximal cut end of the GSP and $3 \mathrm{kDa}$ tetramethylrhodamine dextran amine was applied to the proximal cut end of the CT (Fig. 1). A small amount of Kwik-Sil (World Precision Instruments) was then placed over the cut end of the nerves to prevent crystals from diffusing from the site of the intended label. The IX was isolated medial to the tympanic bulla (Fig. 1). IX was cut peripheral to the petrosal ganglion and placed on a small piece of Parafilm. Crystals of $3 \mathrm{kDa}$ cascade blue dextran amine were applied to the proximal cut end of the IX nerve. All dextran amine conjugates were purchased from Life Technologies. Vaseline and a layer of Parafilm were placed on top of the IX to keep the dextran in place. Animals were then injected with $5 \mathrm{mg} / \mathrm{ml}$ intramuscular Antisedan (atipamezole hydrochloride: Pfizer Animal Health) to promote reversal of anesthesia. After $48 \mathrm{~h}$ survival, animals were deeply anesthetized with urethane and transcardially perfused with KrebsHenseleit buffer, $\mathrm{pH} 7.3$, followed by 4\% paraformaldehyde, $\mathrm{pH}$ 7.2.

As previously established in rats (May and Hill, 2006), we determined in mice that the tracers placed on one nerve did not inadvertently label other nerves, the full complement fibers were labeled as revealed by examinations of the respective ganglia, and the period of survival after surgery was optimal for transport of each anterograde tracer.

\section{Tissue preparation}

Brains were removed, postfixed, and the medulla was blocked and sectioned horizontally on a vibratome at $50 \mu \mathrm{m}$. We chose to section tissue in the horizontal plane because it allows visualization of the entire rostral-caudal and medial lateral extent of the terminal fields in the NTS with the smallest number of sections ( $\sim 10$ sections/mouse). It is also the plane in which the axons branch from the solitary tract and project primarily medially in rodents (Davis, 1988; Whitehead, 1988; Lasiter et al., 1989). It should be noted that a highly detailed description of the mouse NTS and the projection of the CT to this nucleus and subnuclei have been recently described in coronal sections (Bartel and Finger, 2013; Ganchrow et al., 2014).

Sections were then incubated for $1 \mathrm{~h}$ in PBS containing $0.2 \%$ Triton with 1:500 streptavidin Alexa Fluor 488 (Life Technologies) and 1:500 rabbit anti-Cascade Blue (Life Technologies) at room temperature. Streptavidin Alexa Fluor 488 was used to visualize the biotinylated dextran amine-labeled GSP-positive terminals (Fig. $2 B, F, J, N, R, V$ ). Rabbit anti-Cascade Blue was used as a primary antibody to detect Cascade Blue-labeled IX terminal fields and was followed with a $1 \mathrm{~h}$ reaction with 1:500 goat anti-rabbit Cy5 (Jackson ImmunoResearch Laboratories). This secondary antibody was used to visualize IX nerve terminals (Fig. $2 C, G, K, O, S, W)$. Visualization of tetramethylrhodamine, which labeled CT terminal fields, did not require further processing (Fig. $2 A, E, I, M, Q, U)$.

\section{Confocal microscopy and analyses of terminal fields}

Imaging. Terminal fields were imaged using an Olympus IX70 microscope fitted with a Fluoview version 5.0 scanning system and a $10 \times$ objective [UPlanSApo; numerical aperture $(\mathrm{NA})=0.40$ ]. The nerve labels were matched for the wavelengths of the three lasers in the system (argon-ion laser, $488 \mathrm{~nm}$, GSP; helium-neon laser, $543 \mathrm{~nm}$, CT; heliumneon laser, $633 \mathrm{~nm}$, IX). Every $50 \mu \mathrm{m}$ section containing fluorescent terminal field labeling was wet mounted between two coverslips. Sequential optical sections were captured every $3 \mu \mathrm{m}$ for each $50 \mu \mathrm{m}$ section. Images were obtained with settings adjusted so that pixel intensities were near (but not at) saturation. A transmitted light image at $4 \times$ (UPlanSApo; NA $=0.13$ ) and at $10 \times$ was captured for every physical section containing the labeled terminal field. This permitted an accurate registration of dorsal to ventral brainstem sections among animals using common brainstem landmarks $(4 \times)$ and identification of NTS borders $(10 \times)$

Analyses of total terminal field volume. Methods used to analyze terminal field volumes and densities were described previously in detail (Cor- 

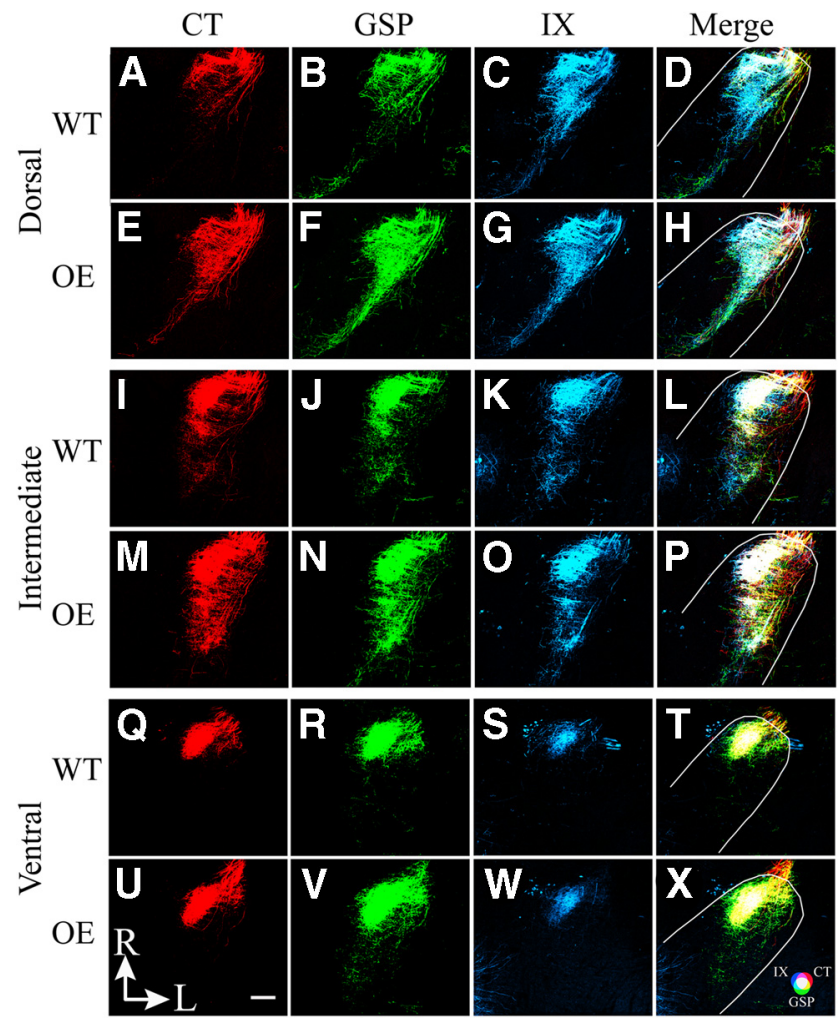

Figure 2. Horizontal sections of labeled terminal fields of the $C T(\operatorname{red} ; A, E, I, M, Q, U), G S P$ (green; $\boldsymbol{B}, \boldsymbol{F}, \boldsymbol{J}, \boldsymbol{N}, \boldsymbol{R}, \boldsymbol{V}$ ), and IX (blue; $\boldsymbol{C}, \boldsymbol{G}, \boldsymbol{K}, \mathbf{O}, \mathbf{S}, \boldsymbol{W}$ ) nerves and for the merged images of all three nerves (MERGE; $\boldsymbol{D}, \boldsymbol{H}, \boldsymbol{L}, \boldsymbol{P}, \boldsymbol{T}, \boldsymbol{X})$ for WT $(\boldsymbol{A}-\boldsymbol{D}, \boldsymbol{I}-\boldsymbol{L}, \boldsymbol{Q}-\boldsymbol{T})$ and $0 \mathrm{E}(\boldsymbol{E}-\boldsymbol{H}, \boldsymbol{M}-\boldsymbol{P}, \boldsymbol{U}-\boldsymbol{X})$ mice in the dorsal $(\boldsymbol{A}-\boldsymbol{H})$, intermediate $(\boldsymbol{I}-\boldsymbol{P})$, and ventral $(\mathbf{Q}-\boldsymbol{X})$ zones within the mouse NTS. The approximate location of the NTS is outlined in white, as shown in the merged images. The CT-GSP overlap is shown as yellow, the IX-GSP overlap is shown as blue-green, the IX-CT overlap in shown as magenta, and the CT-GSP-IX terminal field overlap is shown as white. Refer to the color guide in $\boldsymbol{X}$. Scale bar in $\mathrm{U}, 200 \mu \mathrm{m}$. R, rostral; L, lateral shown in $\boldsymbol{U}$.

son and Hill, 2011; Reddaway et al., 2012). Briefly, quantification of terminal field volume was achieved through the use of custom ImageJbased software. Each image stack was initially rotated so that the solitary tract was oriented vertically. The border of the NTS was outlined for each physical section through the use of the corresponding transmitted light image and the stack was then cropped to include only the NTS. The maximum entropy thresholder algorithm (Sahoo et al., 1988) was then applied to the pixel intensity frequency histogram for the entire image stack, yielding a binary image stack of the pixels above threshold. A particle analysis was then performed to quantify the pixel area above threshold for each channel. Specifically, the number of pixels above threshold for each optical section was summed by ImageJ, converted into area by multiplying the number of pixels by pixel size $(1.38 \mu \mathrm{m} \times 1.38$ $\mu \mathrm{m}$ ), and then multiplied by $3 \mu \mathrm{m}$ (i.e., distance between optical sections) to determine the volume of each label in each physical section. Volumes from each physical section were summed to yield the total terminal field volume for each mouse. The resultant volume represents an unbiased experimenter measure of the amount of label. In addition, the volume of colocalization between the terminal fields of two nerves (CT with GSP, GSP with IX, CT with IX) and among all three nerves (CT, GSP, and IX) was determined in a similar manner as described for each single label.

We chose to include axons (e.g., the solitary tract) along with the terminal field for all animals in our analyses because of the difficulty in accurately deleting these elements from each optical section (Fig. 2). Accordingly, the absolute volumes that we show here include the composite terminal field and axons. Because there is no obvious reorganization of nerve tracts between OE and WT mice, we make the assumption that including the solitary tract in our measurements had a similar quantitative effect among groups.
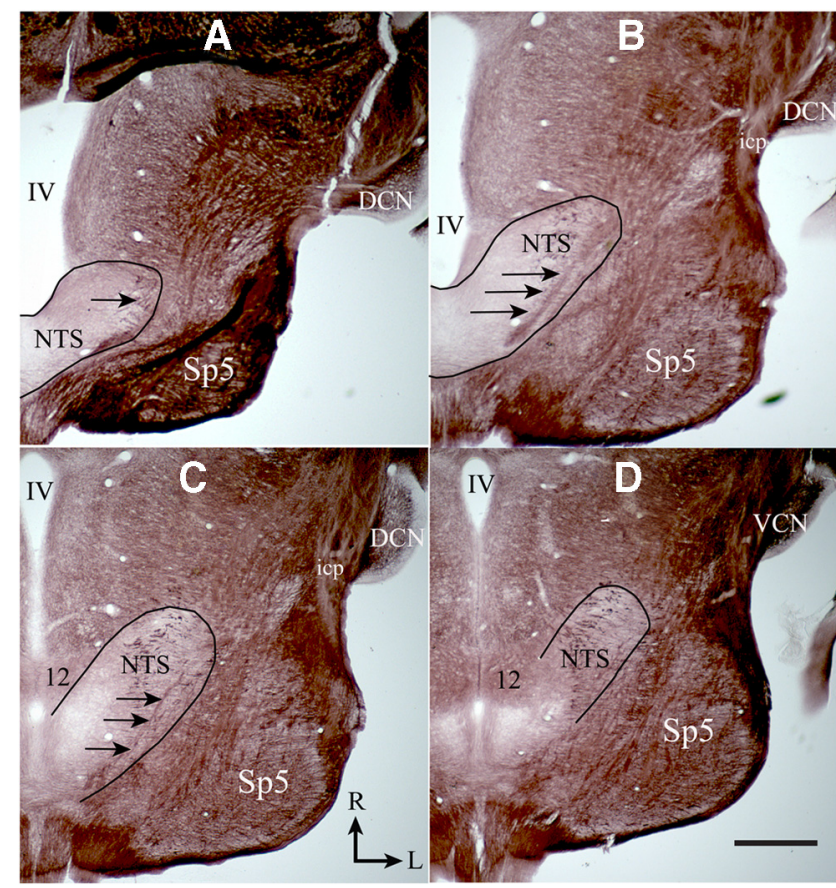

Figure 3. Myelin-stained horizontal brainstem sections in a WT mouse illustrating the shape of the NTS and other brainstem structures at four successive dorsal-ventral levels of the NTS $(\boldsymbol{A}-\boldsymbol{D})$. The NTS is outlined in black and black arrows point to the solitary tract. IV, Fourth ventricle; Sp5, spinal trigeminal nucleus; DCN, dorsal cochlear nucleus; VCN, ventral cochlear nucleus; icp inferior cerebellar peduncle; 12 , hypoglossal nucleus; $R$, rostral; $L$, lateral. Scale bar in $\boldsymbol{D}, 1 \mathrm{~mm}$.

Analyses of terminal field volume and density of labels in dorsal-ventral zones. The NTS was subdivided into $X, Y$, and $Z$ planes to help identify where terminal field organization of each nerve and the overlaps with other terminal fields occurred. For the medial-lateral and rostral-caudal analyses $(X$ and $Y$ ), the NTS in the horizontal plane was subdivided into uniform grid boxes of 100 pixels $\times 100$ pixels. The grid was aligned relative to the NTS, with the intersection of the most medial and most rostral borders of the NTS as the 0,0 coordinate. The density of terminal field label was calculated in each grid box $(100 \times 100$ pixels $)$ for each physical section by dividing the respective terminal field volume within a grid box by the volume of the portion of the NTS contained within the grid box (i.e., volume of terminal field label/volume of the NTS within the grid box). See Corson and Hill (2011) for a detailed description of this method.

For analyses in the dorsal-ventral planes $(Z)$, we examined the volume of labeled terminal field in four dorsal-ventral zones (Fig. 3). This type of analyses is similar to what has been done previously in rat (King and Hill, 1991; Krimm and Hill, 1997; May and Hill, 2006; Sollars et al., 2006; Mangold and Hill, 2008; Corson and Hill, 2011). It should be noted that, like rat, for mouse, the NTS is oriented within the brainstem with the caudal-most portion of the NTS positioned dorsal to the rostral-most portion of the NTS (Ganchrow et al., 2014). That is, the NTS extends ventrally and rostrally from the caudal-most extent of the NTS. Therefore, the far dorsal zone more accurately represents the dorsal-caudal portion of the field in the NTS and the ventral zone represents the more ventral-rostral portion of the terminal field in the NTS.

In horizontal sections, the far dorsal zone is characterized by the sections where the fourth ventricle occupies the largest medial-lateral extent of all zones, where the solitary tract is only seen in the rostral portion of the NTS, where the anterior extent of the rostral pole of the NTS extends no further than the caudal-most $1 / 3$ of the fourth ventricle, and by a lack of the hypoglossal and facial nuclei (Fig. $3 A$ ). This zone included two consecutive sections for each mouse. The dorsal zone also has the fourth ventricle extending in the medial-lateral plane, but less so than in far dorsal zone. The solitary tract extends nearly the entire rostral-caudal 
extent of the NTS, the NTS extends more rostrally than found in far dorsal zone, the inferior cerebellar peduncle is located in the lateral portion of the brainstem, extending rostrally to the dorsal cochlear nucleus, and this zone occupies the sections immediately dorsal to the hypoglossal nucleus (Fig. 3B). The dorsal-most extent of the facial nucleus is present in these sections. Like the far dorsal zone, two sections for each mouse were contained within this zone. The intermediate zone is characterized by a significant thinning of the fourth ventricle compared with the far dorsal and dorsal zones, the solitary tract is thinner and shorter than seen in the dorsal zone, the rostral pole of the NTS extends further anteriorly than in the dorsal zone, the inferior cerebellar peduncle is wider than in the dorsal zone, and both the hypoglossal and facial nuclei are evident (Fig. 3C; facial nucleus not shown). Three sections were in the intermediate zone for each animal. The ventral zone is at the level ventral to the fourth ventricle, the NTS is less defined and narrow at its rostral extent, the ventral cochlear nucleus is apparent, and the inferior cerebellar peduncle is difficult to see. The hypoglossal and facial nuclei are clearly seen in this zone (Fig. 3D). The remainder of sections with terminal field label ( $\geq 4$ sections) is located in this zone.

These landmarks were consistent between the two groups. To check for reliability, a person naive to previous assignment of sections into zones assigned sections for each animal into the four zones. With minor exceptions, the dorsal-ventral zone assignments among investigators were the same.

\section{Statistical analysis}

Terminal field volumes. The mean \pm SEM was calculated for the total CT, GSP, and IX nerve terminal field volumes, for their overlapping field volumes, and for terminal field volumes within the four defined dorsalventral zones. Comparisons were made for the volume of each nerve and overlap between OE and WT groups using independent-samples $t$ tests. The Holm-Šídák step-down test was used to correct for multiple comparisons. We chose to start the step-down process with the unadjusted $\alpha$ level at 0.05 (Holm, 1979).

Density by dorsal-ventral zones. Density measures were not analyzed statistically, but were qualitatively examined through heat maps for each dorsal-ventral zone containing a $5 \times 10$ (column $\times$ row) grid.

Examination of terminal fields in coronal sections. The NTS from two OE (females, $>90 \mathrm{~d}$ old) and two WT mice (females, $>90 \mathrm{~d}$ old) were sectioned coronally on a vibratome at $50 \mu \mathrm{m}$ and imaged as described above. Coronal sections were used to examine the extent of terminal field expansion and overlapping fields in the NTS. No quantitative measurements were taken. Coronal sections were also imaged with transmitted light after confocal microscopy of the fluorescently labeled terminal fields to allow visualization of labeled chorda tympani nerve terminal fields in coronal sections.

Geniculate ganglion and petrosal ganglion cell number. All mice were at least 3 months old. The CT (OE, $n=8: 4$ males, 4 females; WT, $n=4: 2$ males, 2 females) or the GSP (OE: $n=5,2$ males, 3 females; WT: $n=5$, 2 females, 3 males) nerve was labeled as described for the terminal field labeling procedure, with the exception that tetramethylrhodamine was chosen as the only tracer because it did not require further processing for visualization. This allowed us to image the entire intact ganglion, thereby allowing us to count all labeled cells. After cardiac perfusion, geniculate ganglia were removed and postfixed. Petrosal ganglia (OE: $n=9,6$ males, 3 females; WT: $n=4,2$ males, 2 females) were also labeled by way of the IX using the tetramethylrhodamine tracer and collected as described for the geniculate ganglia. Each intact ganglion was then placed between two coverslips and imaged on a scanning laser confocal microscope. Serial 2 $\mu \mathrm{m}$ optical sections were taken throughout each ganglion, as described previously in rat (Shuler et al., 2004). Cell number was determined using Neurolucida computer software (version 4.34; MicroBrightField), also as described previously (Shuler et al., 2004).

Ganglion cell number was compared between OE and WT mice and analyzed using independent-samples $t$ tests. As noted in the statistical description for terminal field analyses, the Holm-Š́dák step-down test was used to correct for multiple comparisons of ganglion cell numbers. We chose to start the step-down process with the unadjusted $\alpha$ level at 0.05 (Holm, 1979).

\section{CT nerve neurophysiology}

All animals were at least 3 months old. Mice (WT; $n=6: 3$ male, 3 female; $\mathrm{OE}, n=6: 4$ male, 2 female) were anesthetized as described for the "Fluorescent Anterograde Nerve Labeling" procedure. The animals were tracheotomized and placed on a circulating water heating pad to maintain body temperature. Hypoglossal nerves were transected bilaterally to prevent tongue movement and the mouse was placed in a nontraumatic head holder. The left CT was isolated using a mandibular approach. The nerve was exposed near the tympanic bulla, cut, desheathed, and positioned on a platinum electrode. A second electrode was placed in nearby muscle to serve as ground. Kwik-Sil was placed in the cavity around the nerve. Whole-nerve CT activity was fed to a Grass Instruments low impedance input stage amplifier and then led to a Grass Instruments P511 amplifier. The filtered signal was integrated (time constant, $1.0 \mathrm{~s}$ ) and was led to and analyzed with PowerLab Scope software and A/D hardware (ADInstruments). Output of the PowerLab was fed to an audio monitor and to a computer monitor for monitoring activity.

Stimulation procedure. All chemicals were reagent grade and prepared in artificial saliva (Hellekant et al., 1985). Neural responses were recorded to ascending concentrations series of $0.05,0.1,0.25$, and $0.5 \mathrm{M} \mathrm{NaCl}$, to 10,20 , and $50 \mathrm{~mm}$ citric acid, and then to $0.1,0.25,0.5$ and $1.0 \mathrm{M}$ sucrose. (Responses to quinine hydrochloride were not recorded because of low response magnitudes to relatively high stimulus concentrations.) Each concentration series was bracketed by applications of $0.5 \mathrm{M} \mathrm{NH}_{4} \mathrm{Cl}$ to monitor the stability of each preparation and for normalizing taste responses. Solutions were applied to the tongue in $5 \mathrm{ml}$ aliquots with a syringe and allowed to remain to the tongue for $\sim 20 \mathrm{~s}$. We used this period of stimulation so that we could ensure enough of a period to measure steady-state responses. After each solution application, the tongue was rinsed with artificial saliva for $\geq 1$ minute when the stimulus concentrations were high. This period allows for full recovery of neural responses (i.e., the responses were not adapted by previous responses; Shingai and Beidler, 1985). CT responses were calculated as follows: the average voltage of the spontaneous activity that occurred for the second before stimulus onset was subtracted from the voltage that occurred from the period from the first to sixth second after stimulus application. Response magnitudes were then expressed as ratios relative to the mean of $0.5 \mathrm{M} \mathrm{NH}_{4} \mathrm{Cl}$ responses before and after stimulation. Whole nerve response data were retained for analysis only when $0.5 \mathrm{M} \mathrm{NH}_{4} \mathrm{Cl}$ responses that bracketed a concentration series varied by $<10 \%$. In addition, responses were recorded to the $\mathrm{NaCl}$ concentration series in the epithelial sodium channel blocker amiloride $(50 \mu \mathrm{M})$. Rinses during this series were to amiloride.

\section{RT-PCR analysis of BDNF expression in tongue, palate, geniculate ganglion, and NTS}

Tissue collection. To establish that the $\mathrm{OE}$ mice used here overexpressed $\mathrm{BDNF}$ at a higher level in the tongue than seen in WT mice, we used RT-PCR procedures similar to that of Huang and Krimm (2010). Moreover, to test hypotheses relating BDNF overexpression to changes in terminal fields, we also examined BDNF expression levels in the posterior tongue, nasoincisor duct in the palate, geniculate ganglia, and the NTS in $\mathrm{OE}$ and WT mice (Fig. 1).

The anterior $2 / 3$ of fresh tongues from OE ( $n=3: 2$ male, 1 female) and WT littermates ( $n=3: 2$ males, 1 female) were collected and cut at the midline, rinsed with cold PBS, and then incubated in sterile dispase I-solution (BD Biosciences) for $60 \mathrm{~min}$ at $37^{\circ} \mathrm{C}$. Epithelial sheets of the tongue were then peeled from the underlying mesenchyme and transferred into separate tubes containing RNAlater (Ambion) and then stored at $-80^{\circ} \mathrm{C}$ until RNA extraction. Similarly, tissue that included the nasoincisor duct, foliate papillae, and circumvallate papillae (WT; $n=3$; 1 male, 2 female: OE; $n=4 ; 2$ males, 2 females) were collected and treated as described for anterior tongue. Fresh geniculate ganglia (WT, $n=4: 2$ males, 2 females; OE, $n=6: 2$ males, 4 females) and NTS (WT, $n=6: 3$ males, 3 females; OE, $n=8: 4$ males, 4 females) were dissected and stored in RNAlater until RNA extraction. All mice were at least 3 months old.

RNA extraction and measurement. Total RNA from oral epithelia, geniculate ganglia, and NTS, was extracted using RNeasy micro kit or RNeasy mini kit (Qiagen). Traces of DNA were eliminated in samples by 
treatment with DNase I. Total RNA was analyzed with Nanodrop 2000c (Thermo Scientific) and with RNA 6000 Pico/Nano Chip kits in a Bioanalyzer 2100 (Agilent Technologies). RNA integrity numbers (RINs) were used to estimate the RNA quality. Only RNA samples with RIN $>8.0$ were used. Reverse transcription was accomplished with $200 \mathrm{U} \mathrm{Su}$ perscript III Reverse Transcriptase (Invitrogen) and $50 \mathrm{ng}$ of random hexamers (Invitrogen), all in a $25 \mu \mathrm{l}$ reaction volume. The same amount of RNA from control and OE mice was used. RNA was also treated in parallel in the absence of reverse transcriptase to examine for genomic DNA contamination.

PCR was performed by 7500 Fast Real-Time PCR System (Applied Biosystems) using the TaqMan Universal PCR kit (Applied Biosystems) and oligonucleotide primer/probe sets (Huang and Krimm, 2010). TaqMan probes were labeled at the $5^{\prime}$ end with a fluorescent reporter dye (FAM) and at the $3^{\prime}$-end with a quencher dye (TAMRA).

The sequences of primers and probes were as follows: for BDNF, forward primer, TGCAGGGGCATAGACAAAAGG; reverse primer, CTTATGAATCGCCAGCCAATTCTC; probe, ACTGGAACTCGCAA TGCCGAACTACCCA; for GADPH, forward primer, CTGGGACGAC ATGGAGAAGATC; reverse primer, CAACCTGGTCCTCAGTGTAGC; probe, CGTGCCGCCTGGAGAAACCTGCC.

Real-time PCRs were performed in a $20 \mu$ l total volume with $1 \times$ Master Mix 720/200 nm primer/probe sets. PCR efficiencies were determined by performing PCR with serial (10-fold) dilutions of cDNA in parallel. All samples were run in parallel with the housekeeping gene mouse glyceraldehyde 3-phosphate dehydrogenase (GAPDH) to normalize cDNA loading. Each assay was performed in triplicate. PCR was performed for 40 cycles at $95^{\circ} \mathrm{C}$ for $15 \mathrm{~s}$ and at $60^{\circ} \mathrm{C}$ for $1 \mathrm{~min}$.

PCR analyses. For real-time PCR, the comparative $2^{-\Delta \Delta C T}$ method was used to determine the relative $B D N F$ gene expression levels (Huang and Krimm, 2010). The normalized expression of the BDNF was calculated as normalized expression $=\left(E_{\mathrm{BDNF}}\right)_{\text {target }}^{\Delta \mathrm{CT}}$ (control - sample $){ }^{\prime}$ $\left(E_{\text {ref }}\right)_{\mathrm{GAPDH}(\text { control - sample) }}^{\Delta \mathrm{CT}} E_{\mathrm{BDNF}}$ and $E_{\mathrm{GAPDH}}$ represent the reaction efficiency of the respective gene, and $\Delta \mathrm{CT}$ is the cycle difference between the control and the sample.

\section{Results}

BDNF is overexpressed throughout the epithelia in OE mice As expected, our RT-PCR data showed that BDNF expression in the anterior tongue of $\mathrm{OE}$ mice was significantly greater $(581 \times)$ than that in WT mice $(p<0.0001$; Fig. 4$)$. This is consistent with previous reports of increased BDNF protein levels in OE mice (LeMaster et al., 1999). We also found that BDNF expression in the nasoincisor duct, foliate, and circumvallate papillae were $348 \times, 343 \times$, and $63 \times$, respectively, that found in WT mice $(p<$ 0.0001 ; Fig. 4). In contrast, the relative expression levels of BDNF for geniculate ganglia and for the gustatory region of the NTS did not differ by genotype ( $p>0.05$; Fig. 4$)$.

\section{Total terminal field volumes in BDNF OE mice are larger compared with WT mice}

With the exception of the labeled terminal field volume for IX and the overlap between IX and CT, the total amount of labeled terminal fields were significantly greater for each nerve and every combination of terminal field volume overlaps in OE mice compared with WT mice (Fig. 5; $p<0.05$ ). The mean terminal field volumes for the CT, GSP, CT overlap with the GSP, IX overlap with the GSP, and the overlap among all three nerves in OE mice were $105 \%, 83 \%, 95 \%, 88 \%$, and $110 \%$ greater, respectively, compared with means in WT mice (Fig. 5). Although the IX terminal field volume in OE was $47 \%$ and the overlap between IX and CT was $100 \%$ greater than in WT controls, these differences were not significantly different, most likely because of the variance seen in OE mice for the IX label (Fig. 5). The medians for the IX terminal field were 101.0 and 116.3 for the WT and OE group, respectively, further illustrating the similarity between groups.

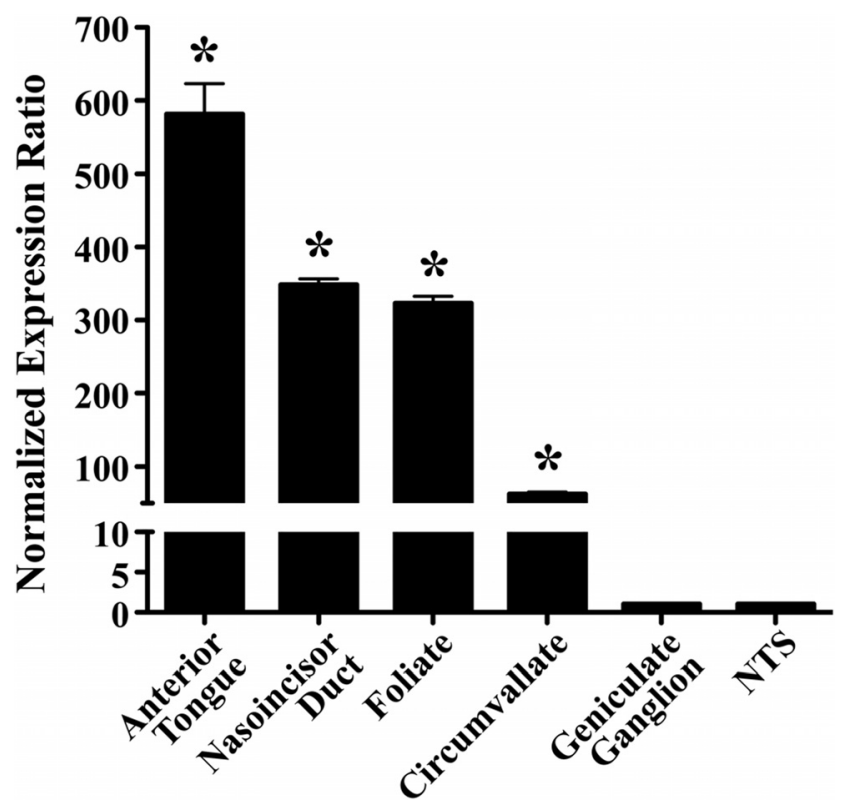

Figure 4. Mean ( \pm SEM) normalized expression levels of BDNF in the anterior tongue, nasoincisor duct, foliate papillae, circumvallate papillae, geniculate ganglion, and NTS in BDNF overexpressor mice. Means were calculated to the respective expression levels in WT mice. The expression ratio of 1.0 represents the WT mean. ${ }^{*} p<0.05$ compared with WT mice.

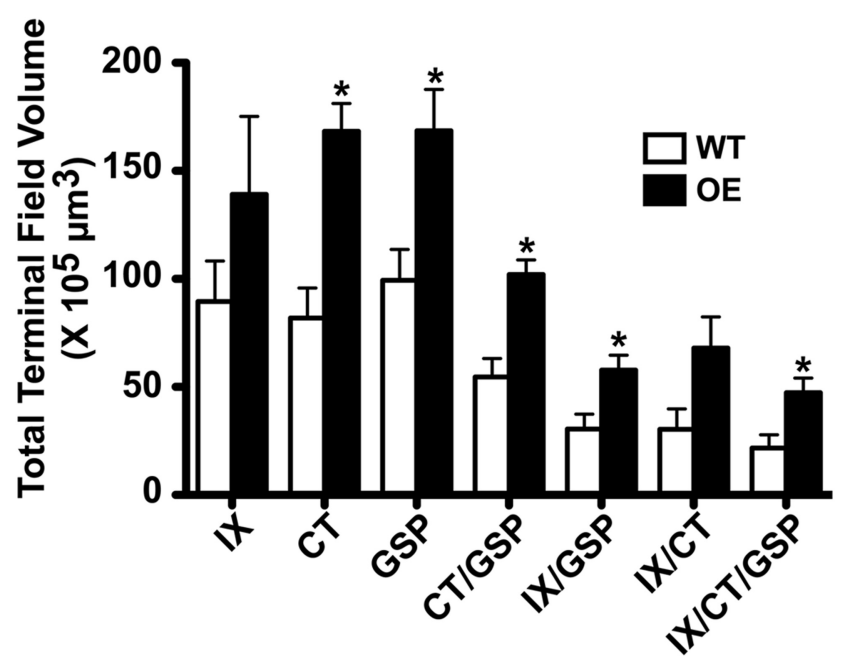

Figure 5. Mean ( \pm SEM) total terminal field volumes of the terminal field for the $I X, C T$, and GSP nerves and their double and triple overlap of terminal fields in WT (open bars) and OE (solid bars) mice. ${ }^{*} p<0.05$.

Expansion of the terminal fields with increases in terminal field densities occur in all dorsal-ventral zones

To further examine the group-related differences in terminal field organization of the three nerves and their overlapping fields, we examined differences between OE and WT mice in the volume and density of label in each of the four zones described earlier.

\section{Far dorsal zone}

Volume: WT mice. The amount of terminal field label in this dorsal-most zone contained the least amount of label of all four zones in WT mice. Whereas all 6 WT mice had label in this zone, only the ventral-most section of the two $50 \mu \mathrm{m}$ sections comprising this zone contained label. There was relatively more IX label in this zone compared with CT and GSP label (Fig. 6A). The relatively low amounts of CT and GSP label resulted in corre- 
spondingly smaller amounts of label where the nerves overlapped with other fields (Fig. 6A).

Volume: OE mice. Of the six OE mice, five had label contained in the far dorsal zone, two with label in both $50 \mu \mathrm{m}$ sections. In contrast to WT mice, there were similar amounts of label for the IX, CT, and GSP, resulting in areas of overlap among the three nerves (Fig. 6A). Compared with WT mice, OE mice had significantly more label $(p<0.05)$ for the CT (10.2 $\times$ greater), GSP ( $4.7 \times$ greater $)$, and the overlap between the IX and CT nerve terminal fields (9.7 $\times$ greater) (Fig. 6A). None of the other comparisons was significantly different.

Density. The densities of label are depicted in the heat maps shown in Figure 6, $B, D, F$, and $H$. For brevity, we show only the heat maps for the three nerves (CT, GSP, IX) and the heat map for the triple overlap (CT with GSP with IX). The heat maps for all three nerves and the overlaps for WT and OE mice were normalized to the grid box with the highest label density from the eight fields. For example, in the far dorsal zone, the grid box with the highest density of label occurred for the IX label in OE mice (see white rectangle in Fig. $6 B)$. That value (192.8; total volume of terminal field label in a grid box/total volume for respective grid box $\times 10^{3}$ ) was used as $100 \%$ intensity and all other density measures in this zone (volume of terminal field label/volume of the NTS contained within the grid box $\times 10^{3} \mu \mathrm{m}^{3}$ ) were made relative to it (see heat map scale in Fig. $6 B$ ).

Density: WT mice. As a result of relatively more IX label in this zone (Fig. 6A), the greatest density of IX label was contained in the rostral most portion of the NTS in WT mice (Fig. 6B). The label for $\mathrm{CT}$ and GSP was also distributed in the rostral most portion of the NTS (Fig. $6 B$ ).

Density: OE mice. The patterns of labels were similar between $\mathrm{OE}$ and WT mice for the three nerves and for the triple overlap of these nerves. However, as seen in Figure $6 B$, there are regions of high density for the IX, CT, and GSP label in the NTS in $\mathrm{OE}$ mice, which are not seen in WT mice. This reflects the large volume differences noted for the three nerves (Fig. 6A). Figure $6 B$ also shows that the label in OE mice extended more caudally and generally more medially than in WT mice. The densities were not as qualitatively different between groups for the triple label measures as seen for the terminal fields of the single nerves.

\section{Dorsal zone}

Volume: WT mice. There was more terminal field label in this zone for the three nerves and areas of overlap compared with label seen in the far dorsal zone (Fig. 6C). All WT mice had label in this region. The IX label continued to be the most prevalent in this zone; how-
VOLUME

DENSITY
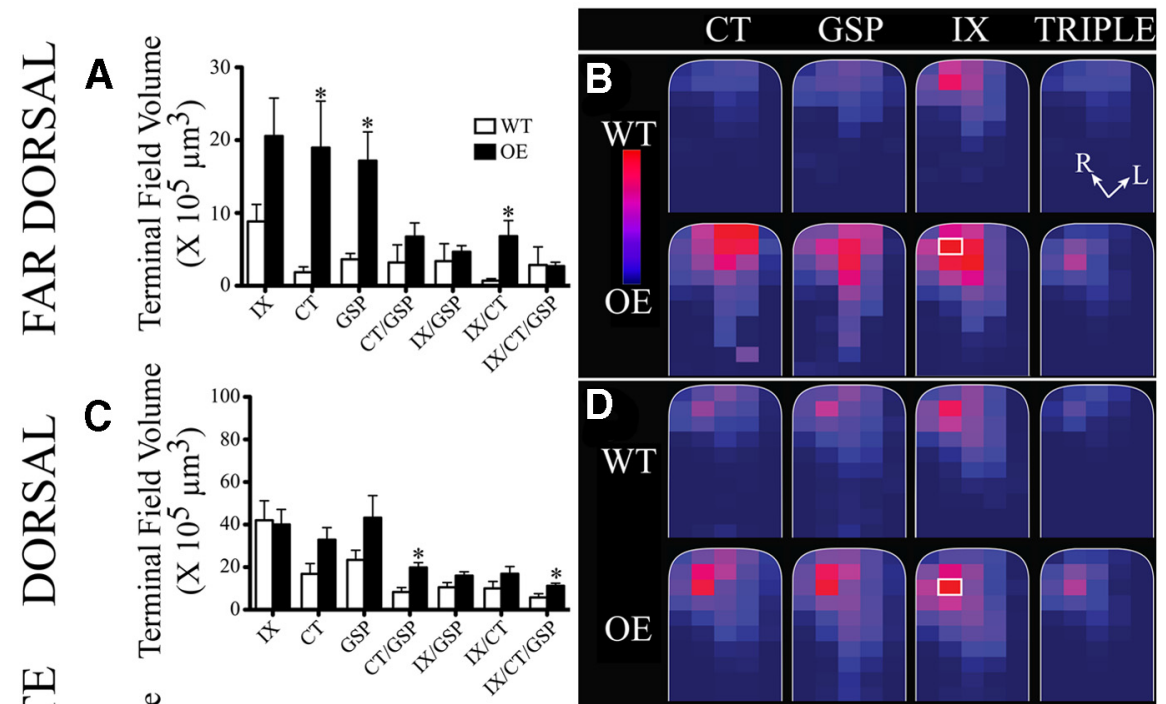

Figure 6. Mean ( \pm SEM) terminal field volumes and densities in $x, y$, and $z$ planes in WT and OE mice. $\boldsymbol{A}, \boldsymbol{C}, \boldsymbol{E}, \boldsymbol{G}$, Mean ( \pm SEM) terminal field volumes of the CT, GSP, and IX nerves and their overlapping fields for WT (open bars) and OE (solid bars) mice in the far dorsal $(\boldsymbol{A})$, dorsal $(\boldsymbol{C})$, intermediate $(\boldsymbol{E})$, and ventral $(\boldsymbol{G})$ zones. Asterisks shown for terminal field volumes denote $0 \mathrm{E}$ means significantly greater than in WT mice $(p<0.05)$. $\boldsymbol{B}, \boldsymbol{D}, \boldsymbol{F}, \boldsymbol{H}$, Heat maps showing the terminal field densities (volume of terminal field label in a division/total volume of the division) for CT, GSP, and IX nerves and for the triple overlap of all three nerve terminal fields (TRIPLE). The NTS (borders shown in white) has been rotated so that the solitary tract is oriented vertically (see Materials and Methods section and see $\mathrm{R}$, rostral, and L, lateral orientations in $\boldsymbol{B}$, TRIPLE overlap). The NTS for each zone is divided into a maximum of $100 \times 100$ pixel divisions for each optical image (see Materials and Methods). The colors for the heat map of densities are on the relative scale shown in B, with $0 \%$ of maximum density noted as dark blue and $100 \%$ noted as red. This relative scale was applied to each of the fou zones; therefore, the maximum density was obtained from all of the divisions from WT and OE mice for the far dorsal zone, and similarly for the dorsal, intermediate, and ventral zones. The division representing $100 \%$ (brightest red) in $\boldsymbol{B}, \boldsymbol{D}, \boldsymbol{F}$, and $\boldsymbol{H}$ are shown by a white border around the respective $100 \times 100$ pixel division (e.g., contained in the $I X$ terminal field of $0 E$ mice in the far dorsal zone).

ever, significant amounts of CT and GSP label also occurred in WT mice (Figs. $2 A-C, 6 C$ ). Moreover, there were corresponding fields of overlap for two-nerve overlaps and the triple overlap (Figs. 2D, 6C).

Volume: OE mice. Similar to the label seen in the far dorsal zone, all three nerves had similar volumes of label in this zone (Fig. 6C) in OE mice, which was a much different pattern than that seen in WT mice. However, unlike the more dorsal zone, where the mean label for the three nerves was greater than in WT mice, none was significantly different from that seen in WT mice. The overlapping label between the CT and GSP and the triple overlap label were significantly greater in OE mice compared with WT mice ( $p<0.05 ; 240 \%$ and $194 \%$, respectively; Fig. $6 C$ ). 
Density: WT mice. The shape of the label in WT mice for the dorsal zone extended more caudally in the NTS than seen in the far dorsal zone (Fig. $2 A-C$ ). As seen in Figure $6 D$, the densest portion of the label occurred in the rostral pole of the NTS. As predicted from the terminal field volumes, the IX terminal field had the greatest density of label compared with the other two nerves (Fig. 6D).

Density: OE mice. Similar to the far dorsal region, the grid box with the densest label was for the IX label (white box in Fig. 6D). However, as seen in Figure $6 D$, there are also regions of high density CT and GSP label in the NTS of OE mice, all of which are qualitatively denser and expand more in the NTS than in WT mice. Similarly, the triple overlap of all three nerves in OE mice appears denser and extends more caudally and laterally compared with WT mice (Figs. 2H, 6D).

\section{Intermediate zone}

Volume: WT mice. Unlike the two more dorsal zones in WT mice, the CT and GSP made extensive projections into the intermediate zone, resulting in similar terminal field volumes among the three nerves (Fig. 6E). The projection of all three nerves to the intermediate zone also contributed to substantial amounts of overlapping fields among the three nerves, most notably the relatively large amount of overlap between the CT and GSP (Figs. $2 L, 6 E$ ).

Volume: OE mice. The three nerves also made extensive projections into this zone in $\mathrm{OE}$ mice, with similar mean terminal field volumes. None of the terminal fields was significantly different from that in WT mice ( $p>0.05$; Fig. $6 E)$.

Density: WT mice. There was a similar pattern of density distribution for CT and GSP label in WT mice, with the densest portions located primarily rostral and medial in the NTS (Figs. $2 L, 6 F)$. This is reflected in densest regions of overlap among all three nerves.

Density: OE mice. The densest grid box in this zone was for the CT label (Fig. 6E). This is unlike the more dorsal zones, where the IX label produced the densest projection. The pattern of labeling was similar among the CT, GSP, and the IX (also see triple overlap in Figs. $2 P, 6 F$ ). Although the location of the densest portion of the label was shared with WT mice (i.e., rostral and medial NTS), the label in OE mice extended beyond that seen in WT mice. The extension was primarily caudally and medially for the CT, IX, and triple overlap and caudally and laterally for the GSP (Fig. $6 F$ ).

\section{Ventral zone}

Volume: WT mice. The ventral zone received relatively more CT and GSP label than IX in WT mice (Figs. 2Q-S, 6G). This was reflected in a relatively large proportion of CT and GSP label overlap and small amount of overlap between IX with GSP and IX with CT and a small amount of overlap among all three nerves (Figs. 2T, 6G).

Volume: OE mice. The pattern of terminal field volume in $\mathrm{OE}$ mice was similar to that seen in WT mice; however, the means for the CT, GSP, and CT with GSP overlap were all significantly greater than in WT mice (Fig. 6G). None of the other means was significantly different from in WT mice.

Density: WT mice. The pattern and the densities in the ventral zone were very similar for the CT and GSP in WT mice, with the densest regions in the rostral-medial portion of the NTS (Figs. $2 Q, R, 6 H)$. The IX had a similar pattern of label in this zone, resulting in overlapping fields among all three nerves (Figs. $2 \mathrm{~S}, 6 \mathrm{H}$ ).

Density: OE mice. Unlike the three more dorsal regions, the densest grid box for the ventral zone occurred in the GSP label (white box in Fig. 6H). As noted for the volume measurements,

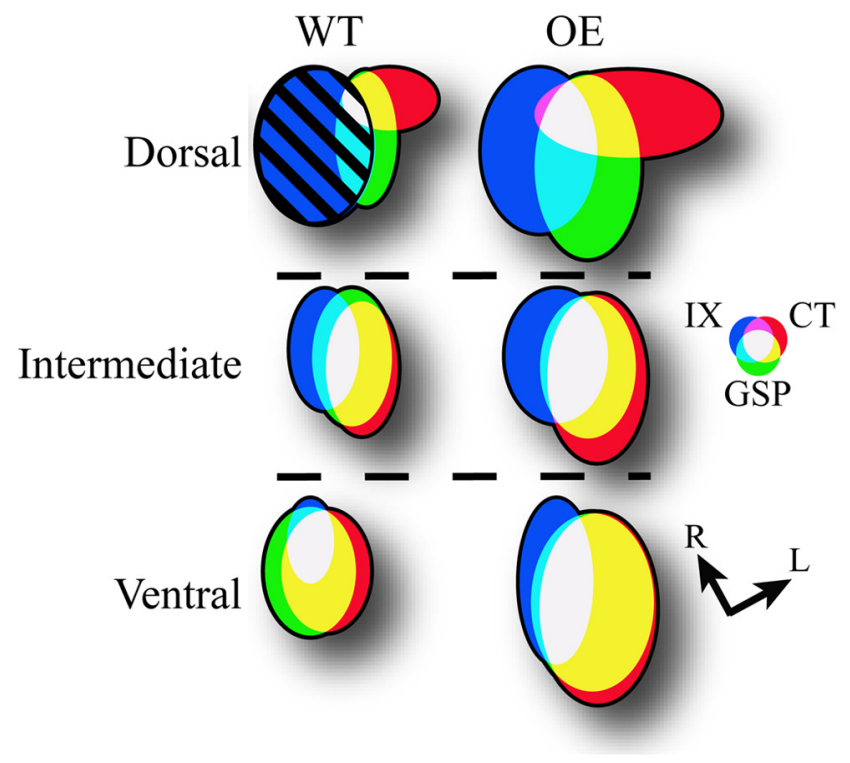

Figure 7. Schematic of the terminal field organization in the NTS in WT (left column) and OE (right column) mice for the dorsal, intermediate, and ventral zones. For comparisons, the total volume of terminal field of the far dorsal and dorsal zones were summed and represented here as the "dorsal zone." The size of the terminal fields were calculated relative to the terminal field volume for the glossopharyngeal nerve in the WT mouse (IX; hatched blue oval in dorsal zone; area $=1.0)$. The color of individual nerves and of their overlaps are shown in the color whee and the orientation of the ovals are shown as they appear in horizontal sections. $R$, rostral; $L$, lateral.

where the means were very similar for the CT and GSP in OE mice, the density patterns appear similar between these two nerves (Fig. 6H). Moreover, the density of label for the CT and GSP was greater in many of the NTS regions compared with WT mice.

\section{Summary}

These results collectively show that there was a $>$ twofold expansion in OE mice of the terminal fields of the CT and the GSP, which innervates anterior tongue and palatal taste buds, respectively. In contrast, the total amount of terminal field of the IX, which innervates taste buds on the posterior tongue, was not affected by the overexpression of BDNF. A detailed density analysis of four dorsal-ventral zones of terminal field label revealed that the location of the densest label in the NTS in each zone was similar between OE and WT mice and the basic shapes of the terminal fields were similar between groups. However, the overall amount of label in each zone and the spread of label appear greater in OE mice compared with WT mice.

Figure 7 shows a summary model of the terminal field organization of the CT, GSP, and IX in the dorsal, intermediate and ventral zones in horizontal sections for WT and OE mice. All terminal fields (and overlapping fields) are generally larger in $\mathrm{OE}$ mice compared with WT mice in the fields throughout the NTS, although the general shape of the fields are similar for both groups (Fig. 7).

\section{Terminal field expansion in the coronal plane}

Figure 8 shows the terminal fields of the three nerves and their triple overlap in the coronal plane. The section shown in the figure is from dorsal-caudal regions of the NTS (Fig. 8I,J) to illustrate corresponding terminal field represented in the dorsal zone noted in Figures 2 and 6. From the label seen in these two animals and confirmed in two additional animals, the amount of 


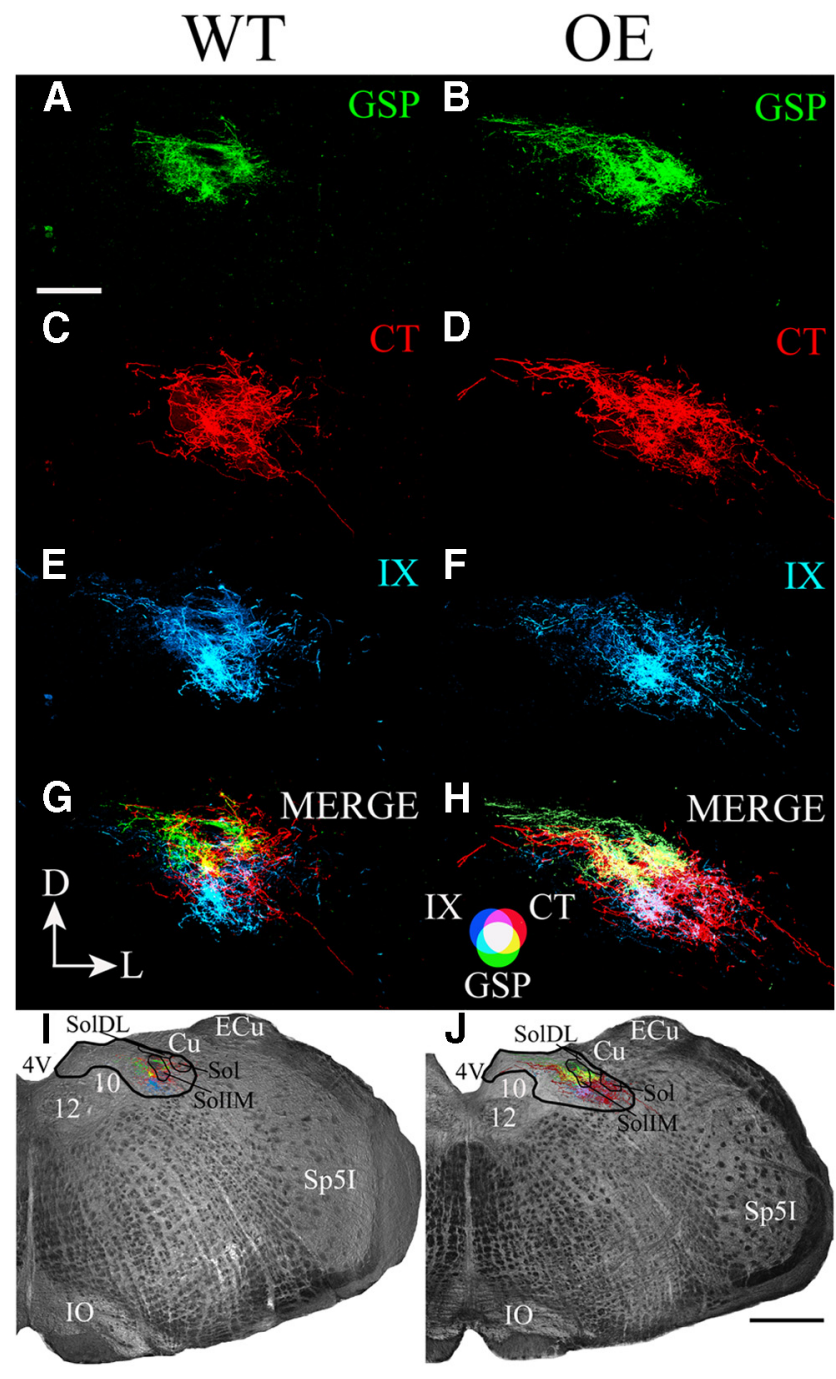

Figure 8. Coronal sections through the dorsal/caudal NTS showing the GSP terminal field (green; $\boldsymbol{A}, \boldsymbol{B})$, CT terminal field (red, $\boldsymbol{C}, \boldsymbol{D})$, IX terminal field $(\boldsymbol{E}, \boldsymbol{F})$, merged $(\boldsymbol{G}, \boldsymbol{H})$ terminal fields, and the terminal fields in the right hemifield of medulla captured with transmitted light $(I, J)$ in WT $(\boldsymbol{A}, \boldsymbol{C}, \boldsymbol{E}, \boldsymbol{G}, \boldsymbol{I})$ and $\mathrm{OE}(\boldsymbol{B}, \boldsymbol{D}, \boldsymbol{F}, \boldsymbol{H}, \boldsymbol{J})$ mice. The orientation of the sections are shown in $\boldsymbol{G}$. $\boldsymbol{D}$, Dorsal; $L$, lateral. The color bar for the merged images in shown in $\boldsymbol{H}$. Scale bars: $\boldsymbol{A}, 200 \mu \mathrm{m} ; \boldsymbol{J}$, $500 \mu \mathrm{m}$. The black lines shown in I and $J$ demarcate the NTS (thicker lines) and structures within the NTS (thinner lines). 4V, Fourth ventricle; 12 , hypoglossal nuclei; 10 , dorsal motor nucleus of the vagus; $\mathrm{Cu}$, cuneate nucleus; $\mathrm{ECu}$, external cuneate nucleus; $\mathrm{Sp5I}$, spinal trigeminal nucleus interpolar, I0, inferior olive; Sol, solitary tract; SollM, solitary tract nucleus, intermediate; SolDL, solitary tract, dorsolateral. Black lines in $I$ and $J$ point to the relevant structure in the NTS.

CT terminal field label and, to a lesser extent, the GSP terminal field label in OE mice extends more medially and laterally than in WT mice (Fig. 8). This pattern is consistent with what is shown in Figure $6, B, D, F, H$.

The pattern of innervation that we see with CT in coronal sections through the NTS of WT mice is similar to that shown in much more detail by others (Bartel and Finger, 2013; Ganchrow et al., 2014).

\section{Ganglion cell numbers are not affected by BDNF overexpression}

BDNF has important roles in determining the early nerve/target matching in developing taste buds, including determining the final number of available neurons (Conover et al., 1995; Liu et al., 1995; Nosrat et al., 1997; Mistretta et al., 1999; Sun and Oakley, 2002; Yee et al., 2003; Ma et al., 2009). Therefore, the neurotro- phin made available in the targets of taste neurons likely plays a role as a chemoattractant for innervating neurons and ultimately determines the final number of innervating neurons and the matching of taste buds with the number of innervating sensory neurons (Nosrat and Olson, 1995; Nosrat et al., 1996; Mbiene and Mistretta, 1997; Krimm and Hill, 1998; Nosrat et al., 2001; Gross et al., 2003). Given this role for BDNF, it is reasonable that more ganglion cells in $\mathrm{OE}$ mice could survive, thereby influencing terminal field organization.

Indeed, as predicted, the total numbers of geniculate ganglion cells in OE mice are $40 \%$ greater than that in WT mice (Krimm et al., 2001). However, this was a total count of all ganglion cells based on stereological measurements, and not counts of CT-, GSP-, or IX-identified neurons.

To more carefully test the hypothesis that group-related changes in terminal field organization can be explained by differences in nerve-specific ganglion cell numbers, we counted the cell soma of the CT and GSP (geniculate ganglion) and of the IX (petrosal ganglion) (Fig. 9A,B). There were no differences in IX, CT, or GSP mean numbers between WT and OE mice (Fig. 9C). The mean ganglion cell number for the IX, CT, and GSP in OE mice was $104 \%, 95 \%$, and $84 \%$ of the respective means in WT mice $(p>0.05)$. Therefore, the larger fields cannot be explained by more neurons providing input into the NTS by way of more of them surviving developmental programmed cell death (Davies, 1994).

\section{Selective functional changes occur in whole nerve taste responses in the $\mathrm{CT}$}

Although the peripheral structural alterations induced by overexpression of BDNF have been well studied (LeMaster et al., 1999; Krimm et al., 2001; Lopez and Krimm, 2006; Ma et al., 2009), there is no information related to the functional consequences of this embryonic manipulation. Given the central structural alterations that we see here, a potential mechanism for the terminal field changes may result from alterations in taste responses. Indeed, activity-dependent mechanisms in shaping central morphologies have been well documented in other sensory systems (Hubel and Wiesel, 1970; Harris and Woolsey, 1981; Smith et al., 1983; Frazier and Brunjes, 1988) and are proposed in the developing gustatory system (May and Hill, 2006; Sollars et al., 2006). To test the hypothesis that alterations in CT taste responses influence terminal field organization, we recorded tasteelicited activity from the whole CT. We chose to record taste responses from the CT because large changes in terminal field organization occurred for this nerve and peripheral taste responses have been studied more in this nerve than in the GSP and IX.

Figure $10 A$ shows the integrated whole nerve responses to a concentration series of $\mathrm{NaCl}$ and the standard response to $0.5 \mathrm{M}$ $\mathrm{NH}_{4} \mathrm{Cl}$ in WT and OE mice. Although responses could be recorded to taste stimuli in $\mathrm{OE}$ mice, the magnitude of the whole nerve response was qualitatively less to all stimuli compared with WT mice. It was necessary to increase the amplification to obtain records similar to that shown in Figure $10 \mathrm{~A}$ for all OE mice. This is a qualitative assessment and, unfortunately, there is no satisfactory way to compare absolute voltages of whole nerve taste responses among animals and between groups because of a number of factors, including potential differences in surgical influences and numbers of axons contacting the electrode (Beidler, 1953). However, it is reasonable that the magnitude of the integrated taste response is less in OE mice because there are fewer taste buds in the anterior tongue compared with WT mice 

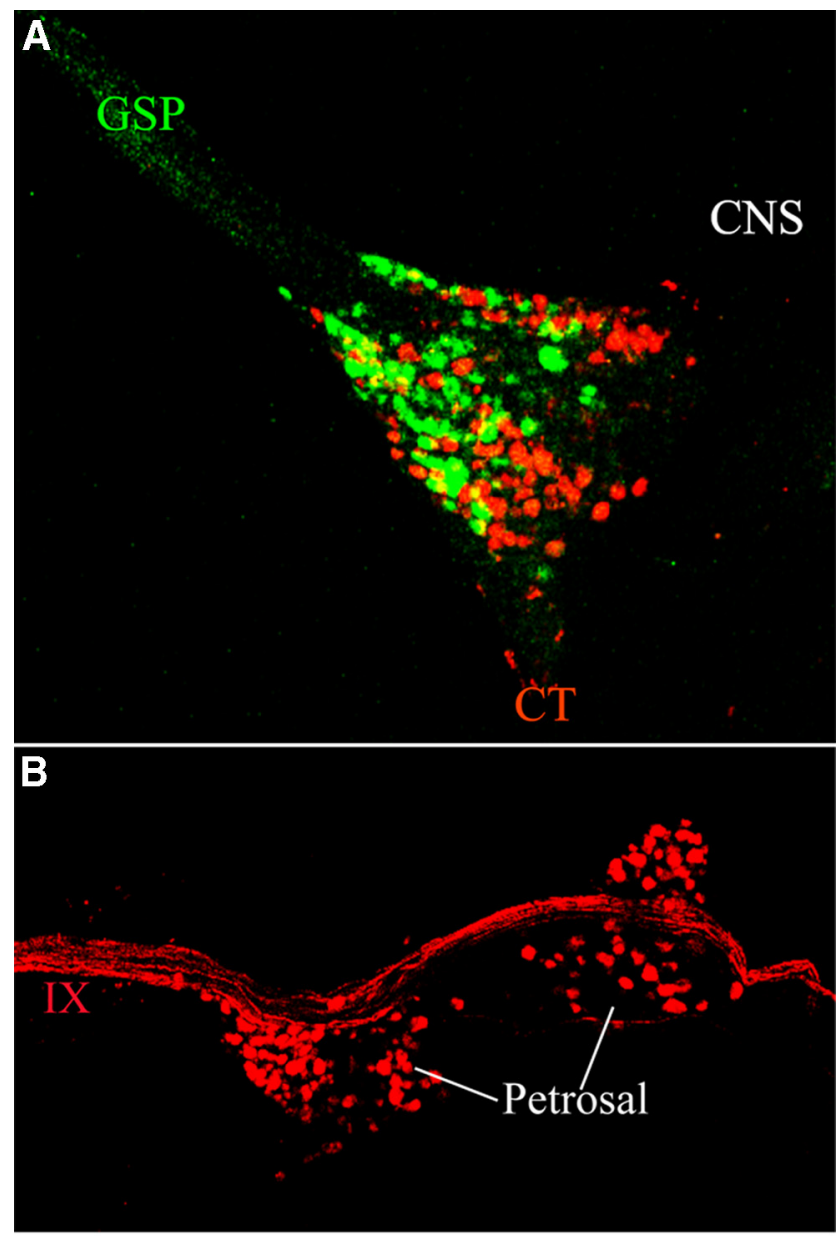

C

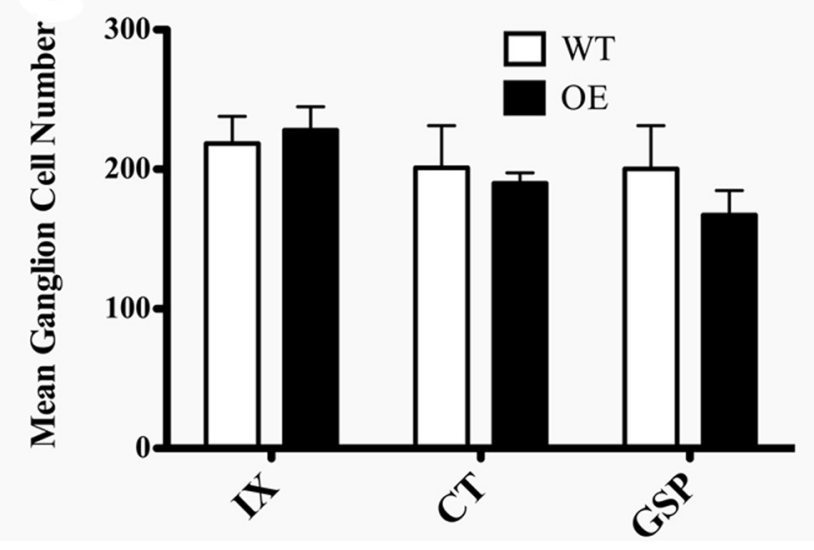

Figure 9. Photomicrograph of the geniculate ganglion $(\boldsymbol{A})$ showing cell soma corresponding to the CT (red) and GSP (green) nerves in $\boldsymbol{A}$ and the petrosal ganglion $(\boldsymbol{B})$ showing cell soma corresponding to the IX nerve (red). Both ganglia are from WT mice. C, Mean ( \pm SEM) ganglion numbers of IX, CT, and GSP neurons in WT (open bars) and OE (closed bars) mice. There were no significant differences between groups for these three nerves.

(Krimm et al., 2001). Therefore, the sensory input to the nerves would likely be less in OE mice.

When normalized to the $0.5 \mathrm{M} \mathrm{NH}_{4} \mathrm{Cl}$ responses, many of the relative responses in OE mice were similar to those in WT mice; however, there was a selective alteration to one taste stimulus. The relative response magnitudes were similar to that seen in WT mice to a concentration series of $\mathrm{NaCl}$ before and after lingual application of the epithelial sodium channel blocker amiloride
(Fig. 10B). Amiloride was equally effective in attenuating the response to $\mathrm{NaCl}$ in both WT and $\mathrm{OE}$ mice (dotted lines in Fig. $10 B)$. There also were no group-related differences in relative taste responses to a concentration series of citric acid (Fig. 10C). Surprisingly, the CT in OE mice responded with larger relative response magnitudes to all concentrations of sucrose, ranging from $2 \times$ to $7 \times$ larger than that in WT mice $(0.2-1.0 \mathrm{M}$; Fig. $10 D$; $p<0.05)$. This result is particularly interesting because other developmental and/or experimental manipulations that result in terminal field changes have corresponding functional relative taste response alterations primarily to $\mathrm{NaCl}$ (Hill and Przekop, 1988; Hill and Phillips, 1994; May and Hill, 2006; Sollars et al., 2006; Reddaway et al., 2012). We must emphasize here that these are relative responses, so group-related differences in $\mathrm{NH}_{4} \mathrm{Cl}$ responses may also be present and would influence the relative response magnitude. It seems unlikely that $\mathrm{NH}_{4} \mathrm{Cl}$ responses differ significantly, however, because no changes occurred to the relative responses to other stimuli and, based on data from rat, the average absolute responses to $\mathrm{NH}_{4} \mathrm{Cl}$ from single neurons (number of action potentials/s) do not change with age, whereas absolute response magnitudes to other stimuli, including sucrose and $\mathrm{NaCl}$, increase dramatically (Hill et al., 1982).

\section{Discussion}

Targeted overexpression of the neurotrophin BDNF in oral epithelia, beginning embryonically, leads to a restructuring of the terminal field organization at the first central gustatory relay in the adult mouse. This was especially apparent for the CT, which has a significant BDNF-induced disruption in peripheral structures as well as a larger and denser terminal field in the brainstem than in WT mice.

\section{Nerve selectivity of terminal field changes}

The fundamental effect of BDNF overexpression on the peripheral gustatory system is an $\sim 60 \%$ loss of fungiform taste buds during development and a disruption of targeting and branching patterns of the CT in the tongue (Lopez and Krimm, 2006; Zaidi et al., 2007). CT axons invade filiform papillae, which are nongustatory structures, in addition to fungiform papillae (Lopez and Krimm, 2006). The remaining fungiform taste buds in OE mice are hyperinnervated by CT neurons (Zaidi et al., 2007) and taste bud loss does not occur in posterior lingual taste buds (Krimm et al., 2001).

We show here that the terminal fields are substantially reorganized for the CT and GSP, but not the IX terminal field (Figs. 2, $6,7)$. Following our hypothesis that BDNF-induced alterations in the peripheral target and in the peripheral limb of taste neurons produce alterations in the central limb of the same nerve, we predicted that the CT terminal field in OE mice would be altered and IX terminal field would be like that in WT mice. This is indeed what we found. A potential mechanism responsible for the presence of BDNF-related effects of reduced taste bud numbers in the anterior but not in the posterior tongue is that the human K14 promoter, used to drive overexpression of BDNF, is expressed progressively from anterior to posterior tongue. Based on studies using the same promoter in neurotrophin knock-out studies (Ma et al., 2009), K14 drives overexpression of BDNF initially in the basal epithelial layer of the anterior tongue (beginning at embryonic day 12.5) and only later in the posterior tongue. Therefore, the overexpression of BDNF occurs in the final stages of axonal guidance of the CT to anterior tongue taste buds (Lopez and Krimm, 2006), but after the period of initial IX nerve targeting to posterior tongue taste buds. The amount of 
overexpression in these tissues may also play a role. All taste bud fields in OE mice overexpress BDNF; however, the anterior tongue expresses $\sim 2 \times$ or more than seen in posterior fields (Fig. 4). Moreover, based on neurophysiological recordings, the IX contains a much smaller percentage of taste-responsive neurons than the CT and GSP (Frank, 1968; Frank, 1991). The IX carries significant tactile and temperature components (Frank, 1968) and is likely to be more sensitive to nerve growth factor (NGF) than to BDNF (Ichikawa and Helke, 1999). Therefore, extensive branching of IX taste fibers in the NTS of OE mice may have occurred, but would be obscured by the large percentage of unaffected NGF-sensitive fibers.

The nerve that does not fit our hypothesis is the GSP. Changes in taste bud numbers were not evident in GSP-innervated taste buds (Krimm et al., 2001). However, we show here that the terminal field is expanded similar to the $\mathrm{CT}$ and that BDNF is highly overexpressed in the nasoincisor duct. This suggests that overexpression levels, and not altered taste bud numbers, may promote the enlarged GSP terminal field size. Unfortunately, the amount of peripheral branching of the GSP was not examined in previous reports, so it is unclear whether the peripheral limb of the GSP was reorganized as seen for the CT.

\section{Postnatal refinement of terminal fields and OE mice}

We propose that the group-related differences in size of terminal fields relate to the postnatal refinement of the fields. Based on findings from rat (Mangold and Hill, 2008) and preliminary work with WT mice (our unpublished data), CT, GSP, and IX terminal fields are large during early postnatal development and are then "pruned" within the first 3-4 weeks postnatally. In OE mice, we suggest that BDNF overexpression yields life-long extensive branching of CT and GSP axons because of a reduced (or lack of) axonal pruning. This is also proposed for rats with an embryonic dietary manipulation (Mangold and Hill, 2008).

The mechanism(s) responsible for this proposed failure to prune is not currently known. However, candidate mechanisms derived from other neural systems may operate here. An abundance of peripherally located BDNF may be transported anterogradely by way of taste neurons to their central terminals, ultimately maintaining (or producing) exuberant branching of CT and GSP axons in the NTS. Anterograde transport of BDNF by peripheral nerves occurs in other systems (Zhou and Rush, 1996; Conner et al., 1997; Altar and DiStefano, 1998; Fawcett et al., 1998; Tonra et al., 1998; Tonra, 1999). Because BDNF drives branching of axonal arbors (Cohen-Cory and Fraser, 1995; Cohen-Cory, 1999; Danzer et al., 2002; Schmidt and Rathjen, 2010; Bilimoria and Bonni, 2013), an increase of BDNF in the soma of CT and GSP neurons could sustain exuberant axonal branches. In addition, sensory neurons (e.g., dorsal root ganglion neurons) partially regulate BDNF release and sensitivity at their terminals by way of autocrine mechanisms (Acheson et al., 1995; Cheng et al., 2011). Such a mechanism could act independently
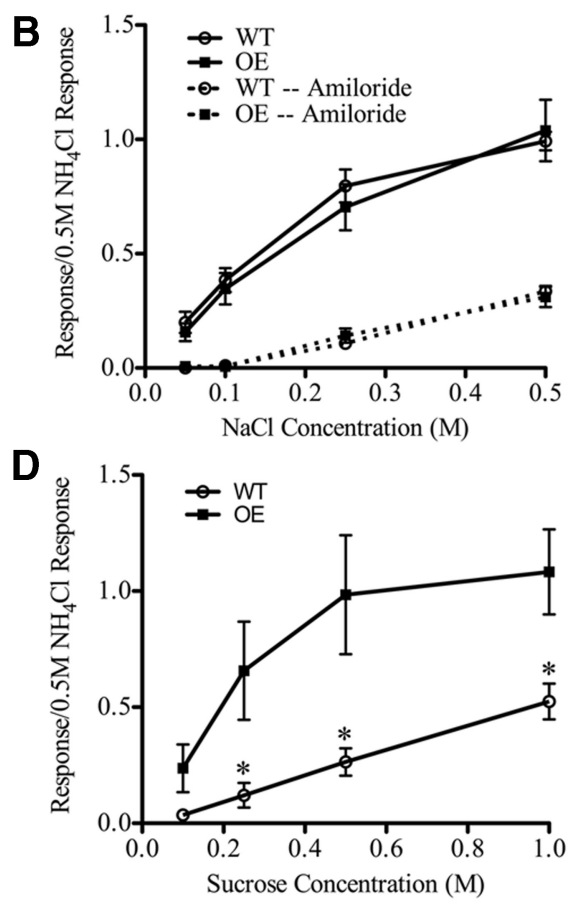

Figure 10. A, Integrated taste responses from the $\mathrm{CT}$ in a WT and $0 \mathrm{E}$ mouse to a concentration series of $\mathrm{NaCl}$ and to $0.5 \mathrm{M} \mathrm{NH} \mathrm{N}_{4} \mathrm{Cl}$. concentration of sucrose $(\boldsymbol{D})$ in WT and OE mice. ${ }^{*} p<0.05$

or in concert with a potential increase in BDNF in the nerves. All of these proposed mechanisms would predict higher levels of localized BDNF protein. In contrast, the BDNF message is not increased centrally (Fig. 4). Other candidate mechanisms participating in the terminal field expansion include cellular processes downstream to BDNF processing and changes in numbers and affinities of BDNF receptors (i.e., TrkB) in OE mice.

\section{Peripheral functional changes as they relate to BDNF overexpression}

One of the most unexpected outcomes of this study was the specific and large group-related increase in the relative responses in the CT to sucrose in OE mice. One explanation could be that there is a higher proportion of "sweet"-containing taste bud cells in OE mice, perhaps as a result of increased innervation. A candidate taste receptor cell would contain the G-protein Gustducin, which is involved in sweet, umami, and bitter taste (McLaughlin et al., 1992; Chandrashekar et al., 2006). However, Zaidi et al. (2007) found no differences in the number of Gustducin cells between the two groups. Instead of changes in "sweet taste" cell numbers, the increased, abnormal innervation in OE mice could influence the distribution and proportion of T1R receptors that underlie sweet taste perception (Nelson et al., 2001; Spector and Travers, 2005; Chandrashekar et al., 2006). For now, these hypotheses are only speculative.

Interestingly, BDNF knock-out mice show a blunted behavioral taste response to sucrose during preweaning ages (Nosrat et al., 1997), suggesting that deletion of BDNF could result in decreased neural sensitivity to sucrose. Through a similar reasoning, overexpression yields a higher sensitivity and perhaps an augmented behavioral response. This sucrose-specific finding in 
OE mice provides a potentially novel functional action of BDNF in the taste system and may participate in determining distinctive membrane properties and excitability of embryonic geniculate ganglion neurons (Al-Hadlaq et al., 2003). As noted earlier, interpretation of whole nerve responses must be made cautiously because they are relative responses.

There also appears to be more global changes in taste responses carried in the CT-a lower response magnitude to all taste stimuli compared with WT mice. The neural signal in all OE mice required a larger amount of amplification than in WT mice for clear integrated taste response records and likely reflects the decreased number of taste buds (Krimm et al., 2001). The overall decreased afferent signal in the CT could reduce the amount of postnatal terminal field pruning, which is proposed to be dependent on taste-elicited activity (May and Hill, 2006).

\section{Potential central functional and behavioral effects of altered terminal field organization in the NTS}

A potential downstream effect of altered taste responses and structural changes in terminal fields in the OE mouse is an altered sensory processing and coding of taste inputs. For example, given the enlarged field of overlap among all three nerves (Figs. 2, 6, 7, 8 ), there is a potential group-related change in the afferent nerve message received by NTS neurons. That is, the change in terminal field along with a potential change in circuitry could lead to altered coding of taste quality and quantity in OE mice. The hypothesized altered functional organization of the NTS in OE mice could in turn lead to altered taste-related behaviors. Alternatively, the reorganized terminal field organization in $\mathrm{OE}$ mice may amplify the reduced afferent inputs that appear to be present at least in the CT. That is, the enlarged fields, and presumably increased numbers of synapses, could compensate for the decreased taste nerve activities.

In short, we show here that the mouse gustatory NTS is especially plastic and has features that make it an ideal system with which to study developmental processes related to nerve/target matching in the brain.

\section{References}

Acheson A, Conover JC, Fandl JP, DeChiara TM, Russell M, Thadani A, Squinto SP, Yancopoulos GD, Lindsay RM (1995) A BDNF autocrine loop in adult sensory neurons prevents cell death. Nature 374:450-453. CrossRef Medline

Al-Hadlaq SM, Bradley RM, MacCallum DK, Mistretta CM (2003) Embryonic geniculate ganglion neurons in culture have neurotrophin-specific electrophysiological properties. Neuroscience 118:145-159. CrossRef Medline

Altar CA, DiStefano PS (1998) Neurotrophin trafficking by anterograde transport. Trends Neurosci 21:433-437. CrossRef Medline

Bartel DL, Finger TE (2013) Reactive microglia after taste nerve injury: comparison to nerve injury models of chronic pain. F1000Research 2:65. CrossRef Medline

Beidler LM (1953) Properties of chemoreceptors of tongue of rat. J Neurophysiol 16:595-607. Medline

Beidler LM, Smallman RL (1965) Renewal of cells within taste buds. J Cell Biol 27:263-272. CrossRef Medline

Bilimoria PM, Bonni A (2013) Molecular control of axon branching. Neuroscientist 19:16-24. CrossRef Medline

Chandrashekar J, Hoon MA, Ryba NJ, Zuker CS (2006) The receptors and cells for mammalian taste. Nature 444:288-294. CrossRef Medline

Cheal M, Oakley B (1977) Regeneration of fungiform taste buds: temporal and spatial characteristics. J Comp Neurol 172:609-626. CrossRef Medline

Cheal M, Dickey WP, Jones LB, Oakley B (1977) Taste fiber responses during reinnervation of fungiform papillae. J Comp Neurol 172:627-646. CrossRef Medline

Cheng PL, Song AH, Wong YH, Wang S, Zhang X, Poo MM (2011) Self- amplifying autocrine actions of BDNF in axon development. Proc Natl Acad Sci U S A 108:18430-18435. CrossRef Medline

Cohen-Cory S (1999) BDNF modulates, but does not mediate, activitydependent branching and remodeling of optic axon arbors in vivo. J Neurosci 19:9996-10003. Medline

Cohen-Cory S, Fraser SE (1995) Effects of brain-derived neurotrophic factor on optic axon branching and remodelling in vivo. Nature 378:192196. CrossRef Medline

Conner JM, Lauterborn JC, Yan Q, Gall CM, Varon S (1997) Distribution of brain-derived neurotrophic factor (BDNF) protein and mRNA in the normal adult rat CNS: evidence for anterograde axonal transport. J Neurosci 17:2295-2313. Medline

Conover JC, Erickson JT, Katz DM, Bianchi LM, Poueymirou WT, McClain J, Pan L, Helgren M, Ip NY, Boland P, Friedman B, Wiegand S, Vejsada R, Kato AC, Dechiara TM, Yancopoulos GD (1995) Neuronal deficits, not involving motor neurons, in mice lacking BDNF and/or NT4. Nature 375:235-238. CrossRef Medline

Corson SL, Hill DL (2011) Chorda tympani nerve terminal field maturation and maintenance is severely altered following changes to gustatory nerve input to the nucleus of the solitary tract. J Neurosci 31:7591-7603. CrossRef Medline

Corson SL, Kim M, Mistretta CM, Bradley RM (2013) Gustatory solitary tract development: a role for neuropilins. Neuroscience 252:35-44. CrossRef Medline

Danzer SC, Crooks KR, Lo DC, McNamara JO (2002) Increased expression of brain-derived neurotrophic factor induces formation of basal dendrites and axonal branching in dentate granule cells in hippocampal explant cultures. J Neurosci 22:9754-9763. Medline

Davies AM (1994) The role of neurotrophins in the developing nervous system. J Neurobiol 25:1334-1348. CrossRef Medline

Davis BJ (1988) Computer-generated rotation analyses reveal a key threedimensional feature of the nucleus of the solitary tract. Brain Res Bull 20:545-548. CrossRef Medline

Erickson RP (1966) Nontraumatic headholder for rats. Physiol Behav 1:97-98. CrossRef

Farbman AI (1980) Renewal of taste bud cells in rat circumvallate papillae. Cell Tissue Kinetics 13:349-357. Medline

Fawcett JP, Bamji SX, Causing CG, Aloyz R, Ase AR, Reader TA, McLean JH, Miller FD (1998) Functional evidence that BDNF is an anterograde neuronal trophic factor in the CNS. J Neurosci 18:2808-2821. Medline

Frank ME (1968) Single fiber responses in the glossopharyngeal nerve of the rat to chemical, thermal, and mechanical stimulation of the posterior tongue. Ph.D. thesis. Providence, RI: Brown University.

Frank ME (1991) Taste-responsive neurons of the glossopharyngeal nerve of the rat. J Neurophysiol 65:1452-1463. Medline

Frazier LL, Brunjes PC (1988) Unilateral odor deprivation: early postnatal changes in olfactory bulb cell density and number. J Comp Neurol 269: 355-370. CrossRef Medline

Fritzsch B, Sarai PA, Barbacid M, Silos-Santiago I (1997) Mice with a targeted disruption of the neurotrophin receptor trkB lose their gustatory ganglion cells early but do develop taste buds. Int J Dev Neurosci 15:563576. CrossRef Medline

Ganchrow D, Ganchrow JR, Cicchini V, Bartel DL, Kaufman D, Girard D, Whitehead MC (2014) Nucleus of the solitary tract in the C57BL/6 J mouse: Subnuclear parcellation, chorda tympani nerve projections, and brainstem connections. J Comp Neurol 522:1565-1596. CrossRef Medline

Gross JB, Gottlieb AA, Barlow LA (2003) Gustatory neurons derived from epibranchial placodes are attracted to, and trophically supported by, taste bud-bearing endoderm in vitro. Dev Biol 264:467-481. CrossRef Medline

Guagliardo NA, Hill DL (2007) Fungiform taste bud degeneration in C57BL/6J mice following chorda-lingual nerve transection. J Comp Neurol 504:206-216. CrossRef Medline

Harris RM, Woolsey TA (1981) Dendritic plasticity in mouse barrel cortex following postnatal vibrissa follicle damage. J Comp Neurol 196:357-376. CrossRef Medline

Hellekant G, af Segerstad CH, Roberts T, van der Wel H, Brouwer JN, Glaser D, Haynes R, Eichberg JW (1985) Effects of gymnemic acid on the chorda tympani proper nerve responses to sweet, sour, salty and bitter taste stimuli in the chimpanzee. Acta Physiol Scand 124:399-408. CrossRef Medline

Hill DL (1987) Susceptibility of the developing rat gustatory system to the 
physiological effects of dietary sodium deprivation. J Physiol 393:413424. Medline

Hill DL, Phillips LM (1994) Functional plasticity of regenerated and intact taste receptors in adult rats unmasked by dietary sodium restriction. J Neurosci 14:2904-2910. Medline

Hill DL, Mistretta CM, Bradley RM (1982) Developmental changes in taste response characteristics of rat single chorda tympani fibers. J Neurosci 2:782-790. Medline

Hill DL, Mistretta CM, Bradley RM (1986) Effects of dietary $\mathrm{NaCl}$ deprivation during early development on behavioral and neurophysiological taste responses. Behav Neurosci 100:390-398. CrossRef Medline

Hill DL, Przekop PR Jr (1988) Influences of dietary sodium on functional taste receptor development: a sensitive period. Science 241:1826-1828. CrossRef Medline

Holm S (1979) A simple sequentially rejective multiple test procedure. Scandinavian Journal of Statistics 6:65-70.

Huang T, Krimm RF (2010) Developmental expression of Bdnf, Ntf4/5, and TrkB in the mouse peripheral taste system. Dev Dyn 239:2637-2646. CrossRef Medline

Hubel DH, Wiesel TN (1970) The period of susceptibility to the physiological effects of unilateral eye closure in kittens. J Physiol 206:419-436. Medline

Ichikawa H, Helke CJ (1999) The coexistence of TrkA with putative transmitter agents and calcium-binding proteins in the vagal and glossopharyngeal sensory neurons of the adult rat. Brain Res 846:268-273. CrossRef Medline

King CT, Hill DL (1991) Dietary sodium chloride deprivation throughout development selectively influences the terminal field organization of gustatory afferent fibers projecting to the rat nucleus of the solitary tract. J Comp Neurol 303:159-169. CrossRef Medline

Krimm RF (2007) Factors that regulate embryonic gustatory development. BMC Neurosci 8:S4. CrossRef Medline

Krimm RF, Hill DL (1997) Early prenatal critical period for chorda tympani nerve terminal field development. J Comp Neurol 378:254-264. CrossRef Medline

Krimm RF, Hill DL (1998) Innervation of single fungiform taste buds during development in rat. J Comp Neurol 398:13-24. CrossRef Medline

Krimm RF, Hill DL (2000) Neuron/target matching between chorda tympani neurons and taste buds during postnatal rat development. J Neurobiol 43:98-106. CrossRef Medline

Krimm RF, Miller KK, Kitzman PH, Davis BM, Albers KM (2001) Epithelial overexpression of BDNF or NT4 disrupts targeting of taste neurons that innervate the anterior tongue. Dev Biol 232:508-521. CrossRef Medline

Lasiter PS, Wong DM, Kachele DL (1989) Postnatal development of the rostral solitary nucleus in rat: dendritic morphology and mitochondrial enzyme activity. Brain Res Bull 22:313-321. CrossRef Medline

LeMaster AM, Krimm RF, Davis BM, Noel T, Forbes ME, Johnson JE, Albers KM (1999) Overexpression of brain-derived neurotrophic factor enhances sensory innervation and selectively increases neuron number. J Neurosci 19:5919-5931. Medline

Liu X, Ernfors P, Wu H, Jaenisch R (1995) Sensory but not motor neuron deficits in mice lacking NT4 and BDNF. Nature 375:238-241. CrossRef Medline

Lopez GF, Krimm RF (2006) Epithelial overexpression of BDNF and NT4 produces distinct gustatory axon morphologies that disrupt initial targeting. Dev Biol 292:457-468. CrossRef Medline

Ma L, Lopez GF, Krimm RF (2009) Epithelial-derived brain-derived neurotrophic factor is required for gustatory neuron targeting during a critical developmental period. J Neurosci 29:3354-3364. CrossRef Medline

Mangold JE, Hill DL (2007) Extensive reorganization of primary afferent projections into the gustatory brainstem induced by feeding a sodiumrestricted diet during development: less is more. J Neurosci 27:46504662. CrossRef Medline

Mangold JE, Hill DL (2008) Postnatal reorganization of primary afferent terminal fields in the rat gustatory brainstem is determined by prenatal dietary history. J Comp Neurol 509:594-607. CrossRef Medline

May OL, Hill DL (2006) Gustatory terminal field organization and developmental plasticity in the nucleus of the solitary tract revealed through triplefluorescence labeling. J Comp Neurol 497:658-669. CrossRef Medline

Mbiene JP, Mistretta CM (1997) Initial innervation of embryonic rat tongue and developing taste papillae: nerves follow distinctive and spatially restricted pathways. Acta Anat (Basel) 160:139-158. CrossRef Medline
McLaughlin SK, McKinnon PJ, Margolskee RF (1992) Gustducin is a tastecell-specific $\mathrm{G}$ protein closely related to the transducins. Nature 357:563569. CrossRef Medline

Mistretta CM, Goosens KA, Farinas I, Reichardt LF (1999) Alterations in size, number, and morphology of gustatory papillae and taste buds in BDNF null mutant mice demonstrate neural dependence of developing taste organs. J Comp Neurol 409:13-24. CrossRef Medline

Nelson G, Hoon MA, Chandrashekar J, Zhang Y, Ryba NJ, Zuker CS (2001) Mammalian sweet taste receptors. Cell 106:381-390. CrossRef Medline

Nosrat CA, Olson L (1995) Brain-derived neurotrophic factor mRNA is expressed in the developing taste bud-bearing tongue papillae of rat. J Comp Neurol 360:698-704. CrossRef Medline

Nosrat CA, Ebendal T, Olson L (1996) Differential expression of brainderived neurotrophic factor and neurotrophin 3 mRNA in lingual papillae and taste buds indicates roles in gustatory and somatosensory innervation. J Comp Neurol 376:587-602. CrossRef Medline

Nosrat CA, Blomlöf J, ElShamy WM, Ernfors P, Olson L (1997) Lingual deficits in BDNF and NT3 mutant mice leading to gustatory and somatosensory disturbances, respectively. Development 124:1333-1342. Medline

Nosrat CA, MacCallum DK, Mistretta CM (2001) Distinctive spatiotemporal expression patterns for neurotrophins develop in gustatory papillae and lingual tissues in embryonic tongue organ cultures. Cell Tissue Res 303:35-45. CrossRef Medline

Oakley B (1998) Taste neurons have multiple inductive roles in mammalian gustatory development. In: Olfaction and Taste XII (Murphy C, ed.), pp 50-57. New York: New York Academy of Sciences.

Oakley B, Brandemihl A, Cooper D, Lau D, Lawton A, Zhang C (1998) The morphogenesis of mouse vallate gustatory epithelium and taste buds requires BDNF-dependent taste neurons. Brain Res Dev Brain Res 105:85-96. CrossRef Medline

Patel AV, Krimm RF (2010) BDNF is required for the survival of differentiated geniculate ganglion neurons. Dev Biol 340:419-429. CrossRef Medline

Patel AV, Huang T, Krimm RF (2010) Lingual and palatal gustatory afferents each depend on both BDNF and NT-4, but the dependence is greater for lingual than palatal afferents. J Comp Neurol 518:3290-3301. CrossRef Medline

Reddaway RB, Davidow AW, Deal SL, Hill DL (2012) Impact of chorda tympani nerve injury on cell survival, axon maintenance, and morphology of the chorda tympani nerve terminal field in the nucleus of the solitary tract. J Comp Neurol 520:2395-2413. CrossRef Medline

Sahoo PK, Soltani S, Wong KC, Chen YC (1988) A survey of thresholding techniques. Comp Vis Graph Image Proc 41:233-260.

Schmidt H, Rathjen FG (2010) Signalling mechanisms regulating axonal branching in vivo. Bioessays 32:977-985. CrossRef Medline

Shingai T, Beidler LM (1985) Response characteristics of three taste nerves in mice. Brain Res 335:245-249. CrossRef Medline

Shuler MG, Krimm RF, Hill DL (2004) Neuron/target plasticity in the peripheral gustatory system. J Comp Neurol 472:183-192. CrossRef Medline

Smith ZD, Gray L, Rubel EW (1983) Afferent influences on brainstem auditory nuclei of the chicken: $N$. laminaris dendritic length following monaural conductive hearing loss. J Comp Neurol 220:199-205. CrossRef Medline

Sollars SI, Bernstein IL (2000) Neonatal chorda tympani transection permanently disrupts fungiform taste bud and papilla structure in the rat. Physiol Behav 69:439-444. CrossRef Medline

Sollars SI, Smith PC, Hill DL (2002) Time course of morphological alterations of fungiform papillae and taste buds following chorda tympani transection in neonatal rats. J Neurobiol 51:223-236. CrossRef Medline

Sollars SI, Walker BR, Thaw AK, Hill DL (2006) Age-related decrease of the chorda tympani nerve terminal field in the nucleus of the solitary tract is prevented by dietary sodium restriction during development. Neuroscience 137:1229-1236. CrossRef Medline

Spector AC, Travers SP (2005) The representation of taste quality in the mammalian nervous system. Behav Cogn Neurosci Rev 4:143-191. CrossRef Medline

Sun H, Oakley B (2002) Development of anterior gustatory epithelia in the palate and tongue requires epidermal growth factor receptor. Dev Biol 242:31-43. CrossRef Medline

Tonra JR (1999) Classical and novel directions in neurotrophin transport and research: anterograde transport of brain-derived neurotrophic factor by sensory neurons. Microsc Res Tech 45:225-232. CrossRef Medline 
Tonra JR, Curtis R, Wong V, Cliffer KD, Park JS, Timmes A, Nguyen T, Lindsay RM, Acheson A, DiStefano PS (1998) Axotomy upregulates the anterograde transport and expression of brain-derived neurotrophic factor by sensory neurons. J Neurosci 18:4374-4383. Medline

Whitehead MC (1988) Neuronal architecture of the nucleus of the solitary tract in the hamster. J Comp Neurol 276:547-572. CrossRef Medline

Whitehead MC, Frank ME, Hettinger TP, Hou LT, Nah HD (1987) Persistence of taste buds in denervated fungiform papillae. Brain Res 405:192195. CrossRef Medline

Yee CL, Jones KR, Finger TE (2003) Brain-derived neurotrophic factor is present in adult mouse taste cells with synapses. J Comp Neurol 459:15-24. CrossRef Medline
Zaidi FN, Krimm RF, Whitehead MC (2007) Exuberant neuronal convergence onto reduced taste bud targets with preservation of neural specificity in mice overexpressing neurotrophin in the tongue epithelium. J Neurosci 27:13875-13881. CrossRef Medline

Zhang C, Brandemihl A, Lau D, Lawton A, Oakley B (1997) BDNF is required for the normal development of taste neurons in vivo. Neuroreport 8:1013-1017. CrossRef Medline

Zhang LL, Ashwell KW (2001) The development of cranial nerve and visceral afferents to the nucleus of the solitary tract in the rat. Anat Embryol (Berl) 204:135-151. CrossRef Medline

Zhou XF, Rush RA (1996) Endogenous brain-derived neurotrophic factor is anterogradely transported in primary sensory neurons. Neuroscience 74 945-953. CrossRef Medline 